\title{
Reconsidering Desire: The Multi-Disciplinary Imperative
}

Assit. Prof. Dr.James Earl

Humanities, Richmond, The American International University in London

\begin{abstract}
In this paper, I will argue that the subject of human desire, and specifically erotic desire, can best be explored with a multi-disciplinary approach in the Humanities, from the standpoints of philosophy and psychotherapy, among others. Using desire as the example, I will then propose a model of cross disciplinary understanding of subjects, which might be used in many other areas of human concern. The tripartite model I propose, including elements of psychology, politics and philosophy, will, I hope, be of use to both theorists and practitioners in various fields. I also intend that the specific treatment here of erotic desire, using this model, will be of immediate interest to both philosophers and psychotherapists. The motivation behind this paper is a keen enthusiasm for what might be characterized as a European Continental, as opposed to Anglo-American, tradition of 'blurring the disciplinary boundaries'- in particular between philosophy and psychotherapy. I am an academic philosopher, and a practicing psychotherapist.
\end{abstract}

Keywords: Reconsidering Desire: the Multi-Disciplinary Imperative 